\title{
CALIBRADOR PORTÁTIL DE MEDIDORES DE ENERGIA
}

\section{ARTIGO ORIGINAL}

ANTUNES, João Vítor Marques ${ }^{1}$

BRAGA, Carmela Maria Polito ${ }^{2}$

FILHO, Clever Sebastião Pereira ${ }^{3}$

ANTUNES, João Vítor Marques. BRAGA, Carmela Maria Polito. FILHO, Clever Sebastião Pereira. Calibrador portátil de medidores de energia. Revista Científica Multidisciplinar Núcleo do Conhecimento. Ano 05, Ed. 01, Vol. 02, pp. 151-175. Janeiro de 2020. ISSN: 2448-0959, Link de acesso: https://www.nucleodoconhecimento.com.br/engenharia-eletrica/calibradorportatil

\section{RESUMO}

Apresenta-se o desenvolvimento de um equipamento para calibração em campo de medidores de energia, portátil e leve, capaz de executar o procedimento de forma otimizada, atendendo às normas técnicas vigentes no Brasil, proporcionando uma redução significativa nos prazos e custos envolvidos no procedimento padrão atual. $O$ instrumento automatiza todos os ensaios necessários, possui carga própria de até $50 \mathrm{~A}$ e imprime, via impressora Bluetooth, um laudo técnico in loco com as principais informações do processo de aferição. São apresentados os requisitos técnicos necessários para que um instrumento deste tipo seja viável e como o calibrador desenvolvido atende a estes requisitos, as vantagens da utilização do mesmo, bem

\footnotetext{
${ }^{1}$ Bacharel em Engenharia Elétrica.

2 Doutorado em Engenharia Elétrica. Mestrado em Engenharia Elétrica. Graduação em Engenharia Elétrica.

${ }^{3}$ Doutorado em Engenharia Elétrica. Mestrado em Engenharia Elétrica. Graduação em Engenharia Elétrica.
} 
como suas principais funcionalidades e características relevantes de hardware e software. O protótipo do equipamento foi calibrado por laboratório acreditado, tendo todas as suas funcionalidades validadas e já possui modelo comercialmente disponível. Trata-se de uma solução de mercado inovadora no sentido de que seu uso otimiza todo o processo da calibração em campo gerando uma redução nos custos e prazos.

Palavras-chave: Calibração em campo, instrumento portátil, padrão de energia, irregularidades e Perdas, carga fantasma.

\section{INTRODUÇÃO}

As Portarias do INMETRO 587 - Regulamento Técnico Metrológico (RTM) para Medidores Eletrônicos de Energia Elétrica Ativa [1] e 285 - RTM para Medidores Eletromecânicos de Energia [2], estabelecem as condições mínimas a serem observadas na apreciação técnica de modelo, na verificação inicial, na verificação após reparos e na verificação por solicitação do usuário/proprietário, em medidores eletrônicos e eletromecânicos de energia elétrica ativa e/ou reativa, monofásicos e polifásicos. Dentre as obrigatoriedades apresentadas, estabelece-se uma metodologia de ensaios para verificação do medidor de energia por solicitação do usuário/proprietário com a possibilidade de realização destes ensaios em campo ou em laboratório. Entretanto, este procedimento é comumente realizado em laboratório por empresas especializadas em calibração, fabricantes de medidores de energia e concessionárias de energia haja vista que não se dispunha de um equipamento portátil desenvolvido especificamente para realizar uma verificação em campo.

Os laboratórios utilizam bancadas, equipadas com uma fonte de tensão e uma fonte de corrente capazes de fornecer a energia necessária para se realizar os procedimentos previstos nas portarias mencionadas em diferentes medidores em várias posições, ou seja, com a possibilidade de se verificar, em geral, de 1 até 20 medidores simultaneamente, dependendo da bancada. Além disso, cada posição destas bancadas possui um medidor padrão de energia, ou seja, um equipamento embutido ou um circuito especializado, com precisão pelo menos três vezes maior que 
a dos medidores sob análise [1][2], capaz de medir a energia que passa através do medidor comum, auxiliando, por exemplo, na obtenção do erro de medição deste último.

Porém, a logística envolvida no processo de mobilização de uma equipe da empresa responsável para retirada do medidor de energia do cliente, instalação de um novo medidor no local, transporte destes medidores até um laboratório credenciado, verificação do funcionamento adequado do mesmo e armazenamento é, muitas vezes, onerosa e demorada, visto que existem empresas que são responsáveis pela distribuição de energia em mais de um estado brasileiro podendo, o transporte de medidores até um laboratório, durar dias. $\mathrm{O}$ artigo 137 da resolução normativa 414 da ANEEL [4] diz que a concessionária deve realizar, em até 30 dias, a aferição de medidores de energia e demais equipamentos de medição que for solicitada pelo consumidor e, apenas com transporte, a empresa pode perder dias valiosos deste período pré-estabelecido. Além disso, segundo [9], para a CEMIG - Companhia Energética de Minas Gerais, em 2010, o custo médio para uma unidade de medidor de energia ser levada a um laboratório para aferição atendendo um chamado do cliente era de $\mathrm{R} \$ 87,00$ e que só neste ano, haviam sido avaliados 5.933 medidores. O fato é que $91 \%$ dos medidores enviados ao laboratório estavam funcionando corretamente e poderiam ter permanecido em campo gerando uma economia de aproximadamente $R \$ 470,00$ mil reais. Ainda segundo [9], este dado foi similar nos 2 anos anteriores a 2010, fazendo com o que a economia atingisse quase $R \$ 1,2$ milhão, não sendo incluídos ainda os medidores cujos clientes, que são convidados a comparecer no processo de aferição de seu medidor, não aparecem e podem solicitar nova verificação caso discordem do laudo anterior. Este ônus existe não só para a CEMIG, mas para toda concessionária brasileira ou empresa especializada que realiza tais procedimentos.

É importante mencionar que o termo "aferição", utilizado neste trabalho, apesar de ter sido removido do VIM - Vocabulário Internacional de Metrologia (VIM) de 2012 [3], descreve o processo de verificação de um equipamento de medição, ou seja, consiste na constatação de que o instrumento sob análise está em conformidade com as 
exigências regulamentares. Essa constatação se dá por meio de comparação do resultado do medidor com um padrão de referência observando-se sua adequação com o erro máximo admissível para uma dada condição de uso [10]. Portanto, tanto o serviço de calibração com ajuste ou somente o comparativo, recebem o mesmo nome de calibração, existindo então, a calibração com ajuste ou a calibração sem ajuste [3]. Neste trabalho, o uso do termo "aferição" visa fazer uma melhor distinção entre os dois processos e facilitar a compreensão já que o termo ainda é usado no meio industrial.

Com base nos fatos apresentados, um equipamento capaz de realizar, em campo, os mesmos procedimentos que uma bancada de laboratório faz, no caso de uma aferição por solicitação do cliente, mas com a praticidade de se emitir um laudo técnico in loco no instante após a aferição atestando o funcionamento adequado ou não do medidor sob teste, elimina os gastos consideráveis da concessionária ou empresa responsável em relação aos medidores que apresentam bom funcionamento. Outro benefício do uso de um equipamento do tipo é a conclusão de todo o processo de aferição em apenas alguns minutos ao invés de até 30 dias, além de trazer maior transparência para o cliente uma vez que toda a aferição é feita na presença do próprio solicitante.

Dessa forma, desenvolveu-se um equipamento, que recebeu o nome fantasia de SMARTEM, capaz de realizar uma aferição ou calibração sem ajustes de medidores de energia em campo ou em laboratório. Porém, com o grande diferencial, em relação a dispositivos de calibração similares, como em [7], em [8] e em [9], que, em geral, possuem apenas um padrão gerenciado por um software de computador, de ser capaz de gerar sua própria carga de até 50A em corrente alternada, com alimentação do equipamento sendo apenas 80VA. Este requisito é de extrema utilidade a fim de reduzir o tempo de calibração em campo como será descrito adiante.

Durante o desenvolvimento do SMARTEM, foram definidas algumas características principais de forma a moldar um produto que, além de possuir os requisitos técnicos necessários para realizar a aferição de medidores de energia, que serão descritos adiante, fosse focado também na experiência do usuário e praticidade. Por esse motivo, todo controle e gerenciamento do equipamento é realizado por um aplicativo 
simples e intuitivo para tablet ou celular com sistema operacional Android®, não sendo necessário seu uso por parte de um especialista da empresa. Além disso, o equipamento foi projetado para possuir um preço viável, ser leve e ter tamanho suficientemente pequeno, além de ergonomia, para ser segurado na mão, atendendo, sua proposta de ser portátil e, por fim, emitir, armazenar, imprimir ou compartilhar um laudo técnico após a realização de uma aferição.

Vale ressaltar o caráter inovador deste equipamento uma vez que, ao ser constatado uma possibilidade de melhoria e otimização de um procedimento padrão adotado atualmente pela maioria das concessionarias de energia ou empresas especializadas em processos de aferição de medidores de energia, desenvolveu-se, desde suas funcionalidades básicas, até seu acabamento final, uma solução simples, mas completa, cujos benefícios funcionais, logísticos e econômicos são favoráveis à sua utilização.

\section{METODOLOGIA DE INSPEÇÃO E ENSAIOS PARA CALIBRAÇÃO}

Medidores de energia, sejam eles eletrônicos ou eletromecânicos, são dispositivos que, basicamente, mensuram a quantidade de energia que passa por eles. Para evidenciar a quantidade de energia medida, cada medidor possui um mostrador, normalmente na unidade $\mathrm{KWh}$, onde é exibido o valor das grandezas registradas pelo equipamento, podendo ser um display digital ou ciclometros. Além disso, os medidores eletromecânicos possuem um disco com uma tarja preta pintada e cada giro deste disco corresponde a uma quantidade de energia consumida, que é descrita pela constante $\mathrm{Kd}$, cuja unidade comumente é Wh/revolução. Em medidores eletrônicos, a constante é conhecida como Ke, mas não há disco. Neste caso, os circuitos do equipamento simulam a ação do disco medindo a energia através de pulsos emitidos por um LED que pisca a cada quantidade Ke de energia medida. A unidade de Ke é, normalmente, Wh/pulso.

Em [1] e [2] são descritos diversos tipos de ensaios para validação de medidores de energia elétrica, tanto eletrônicos como eletromecânicos, porém, o equipamento desenvolvido se propôs a realizar os ensaios exigidos no procedimento de verificação 
por solicitação do usuário/proprietário, que são similares para os dois tipos de medidores existentes. A seguir são descritos os procedimentos para uma aferição na situação mencionada.

\subsection{INSPEÇÃO INICIAL}

O primeiro procedimento do técnico responsável, ao chegar no local onde ocorreu solicitação de verificação por parte do usuário, é avaliar as condições de instalação do medidor para decidir sobre a necessidade ou não da execução dos ensaios. Para isso, ele verifica a integridade dos lacres da concessionária, verifica se o modelo do medidor é o que consta instalado no local e, por fim, avalia a presença de falhas nas ligações ou danos físicos no mesmo. Constatada alguma irregularidade nesta primeira etapa, o medidor é retirado e substituído por um novo sem a necessidade de aferição. Caso contrário, ele inicia o procedimento para realização dos 4 ensaios apresentados a seguir, não necessariamente nesta ordem. Para isso, o técnico responsável deve desconectar o circuito de tensão e corrente do medidor para que o mesmo esteja isolado de qualquer interferência externa no processo de aferição.

Todo este processo é previsto no aplicativo SMARTEM para Android® e mesmo não havendo execução dos ensaios descritos nas próximas etapas, um laudo técnico final é emitido contendo todas as constatações evidenciadas. Vale mencionar que não será necessário que o técnico escreva todas as irregularidades encontradas, visto que o aplicativo permite um pré-cadastro dos tipos de problemas mais comuns, reduzindo o tempo de verificação, uma vez que torna desnecessário para o técnico redigir sobre tudo que encontrou.

\subsection{MARCHA EM VAZIO}

Para este ensaio, deve-se primeiro desconectar o circuito de corrente do medidor, ou seja, não haverá carga. Em seguida, por um determinado tempo, definido pela equação (1) aplica-se uma tensão correspondente à tensão da rede local, em caso de aferição em campo ou, em caso de aferição em laboratório, 115\% da tensão nominal do medidor, para o caso de medidores eletrônico e $110 \%$ da tensão nominal do 
medidor, para o caso de medidor eletromecânico. Se, durante o tempo prédeterminado, o medidor emitir algum pulso ou girar seu disco, significa que está medindo energia sem efetivamente haver uma energia circulante, caracterizando um defeito no mesmo. Caso contrário, o medidor é aprovado no ensaio. Para o caso de medidores polifásicos, um "jumper" é inserido, conectando-se os circuitos de corrente do medidor em série.

$$
t=\frac{900 \times 10^{3} \times K}{N \times V_{N} \times I_{\max }}
$$

Em que:

$\mathrm{t} \quad=$ Tempo de ensaio em minutos

$\mathrm{K}=$ Constante de calibração do Medidor

$\mathrm{N}$ = Número de elementos de medição

$V_{N}=$ Tensão nominal

$I_{\max }=$ Corrente máxima em ampères

Vale ressaltar que, uma das características do calibrador desenvolvido neste trabalho é o fator de potencia unitário. Isto significa que apenas os ensaios em medidores monofásicos seguem estritamente o exigido por norma, já que esse tipo de medidor não realiza medição de carga indutiva ou capacitiva. Já para medidores polifásicos, é comumente utilizado, em campo, um adereço conhecido como "jumper", mencionado anteriormente, para conectar em série os circuitos de corrente dos medidores sob teste, a fim de circular uma corrente monofásica em todas as fases daquele medidor realizando um ensaio com fator de potência 1. Este procedimento não é mais mencionado na norma, mas permite a obtenção de uma aferição apenas aproximada do medidor. Por esse motivo, para aferições em laboratório, recomenda-se o uso de uma bancada trifásica com capacidade de controlar o fator de potencia dos ensaios. 


\subsection{MOSTRADOR}

O objetivo deste ensaio é avaliar se o registrador de medidas, seja ele um display digital ou ciclometros, está medindo de forma correta. Sendo assim, o procedimento consiste na aplicação de $1.0 \mathrm{KWh}$ de energia através do medidor sob teste, observando se o mostrador registrará essa medida de forma adequada. Para isso, aplica-se a tensão da rede nos terminais de tensão do medidor, para o caso de aferição no campo, ou a tensão nominal para o caso de aferição em laboratório. Além disso, aplica-se uma corrente de valor arbitrário, que seja menor que a corrente máxima suportada pelo medidor, a fim de simular o consumo de energia. Neste caso, quanto mais energia circular no medidor, mais rápido será contabilizado $1.0 \mathrm{KWh}$ e, por esse motivo, o equipamento SMARTEM foi projetado para aplicar uma corrente de, aproximadamente, 50A neste ensaio, com o objetivo de realiza-lo no menor tempo possível. Para o caso de medidores polifásicos, um "jumper" é inserido, conectandose os circuitos de corrente do medidor em série. Dessa forma, circulam aproximadamente $45 \mathrm{~A} \pm 10 \%$ em cada uma das fases deste medidor polifásico, tornando o processo ainda mais rápido ao passo que, quanto maior o numero de fases do medidor, mais rápido o mesmo atinge $1.0 \mathrm{KWh}$.

Seria interessante a possibilidade de registro em campo da situação do mostrador do medidor antes e após a realização deste ensaio apenas para reforçar o resultado apresentado pelo dispositivo de calibração utilizado. O aplicativo SMARTEM possui essa funcionalidade possibilitando ao técnico responsável não só realizar registros fotográficos antes e depois do ensaio de mostrador, como também registrar situações da inspeção inicial citadas anteriormente.

\subsection{ENSAIO DE EXATIDÃO}

Neste ensaio, tem-se o objetivo de avaliar se os erros, apresentados pelo medidor sob aferição, estão dentro dos limites estabelecidos por [1] e [2] dependendo da classe do medidor. Para medidores eletromecânicos, o erro percentual não deverá exceder, em campo, $4,0 \%$ para medidores de classe 2 e 2,0\%, para medidores de classe 1 . Para 
medidores eletrônicos, em campo e em laboratório os limites estão indicados para os índices de classe, conforme Tabelas 1 e 2 abaixo.

Tabela 1 - Limites de erros percentuais por classe para medição ativa em campo. Fonte: [1]

\begin{tabular}{|l|l|l|l|}
\hline $\mathbf{D}$ & $\mathbf{C}$ & B & A \\
\hline $\mathbf{\pm 0 , 4}$ & $\pm 1,2$ & $\pm 2,2$ & $\pm 3,2$ \\
\hline
\end{tabular}

Tabela 2 - Limites de erros percentuais por classe para medição ativa em Laboratório. Fonte: [1]

\begin{tabular}{|l|l|l|l|}
\hline $\mathbf{D}$ & C & B & A \\
\hline $\mathbf{0 , 3}$ & $\pm 0,7$ & $\pm 1,3$ & $\pm 2,5$ \\
\hline
\end{tabular}

Além disso, a norma exige que o ensaio deve ser realizado com no mínimo duas condições distintas de carga. No caso do ensaio de medição ativa, é estabelecido que a carga seja entre $10 \%$ da corrente nominal até Imax [1][2].

Dessa forma, são realizados dois ensaios distintos. Para o calibrador portátil SMARTEM, esta distinção se dá pelo nome de Ensaio de Carga Pequena (CP), para uma aplicação de corrente de valor maior ou igual, mas próximo a $10 \%$ da corrente nominal, e Ensaio de Carga Maior (CM), para aplicação de corrente próximo ao valor nominal do medidor. Em ambos os casos, ao fim do ensaio, o aplicativo SMARTEM indica se o erro obtido está em conformidade ou não com os limites estabelecidos em [1] e [2].

\section{DESCRIÇÃO DO EQUIPAMENTO}

Conhecendo-se quais os ensaios e procedimentos que o instrumento SMARTEM deve realizar de forma a atuar como um calibrador portátil em campo, faz-se necessário descrever como o equipamento viabiliza todo este processo levando-se em conta seu tamanho, peso e custo reduzidos, somados a capacidade de geração de carga própria, que são diferenciais em comparação com as bancadas de laboratório e 
calibradores portáteis similares. A seguir são apresentadas as características mais relevantes da sua composição de hardware, abordando seu principio de funcionamento, e de software, destacando suas principais funcionalidades e qualidades.

\subsection{PRINCÍPIO BÁSICO DE FUNCIONAMENTO}

O SMARTEM é um instrumento micro processado desenvolvido para calibrar medidores de energia monofásicos e com possibilidade de se aferir medidores polifásicos, ligando-se o circuito de corrente destes medidores em série. Para isso, requer que o medidor a ser aferido seja desconectado da rede proveniente da concessionaria de energia e também desconectado da carga ou cliente de forma a permitir que apenas o dispositivo calibrador controle o fluxo de energia sobre o medidor de energia em aferição.

Internamente, o equipamento possui dispositivos eletroeletrônicos que habilitam uma saída com sinal de tensão, corrente e uma entrada para captação de pulsos. Para garantir a segurança em relação a operação do mesmo, conta com elementos de segurança ativados via programação ou via atuação mecânica. $O$ diagrama de blocos da Figura 1 mostra a sequência básica de operações do instrumento, a partir do controle através do aplicativo SMARTEM.

Figura 1 - Sequencia de Operações do Instrumento.

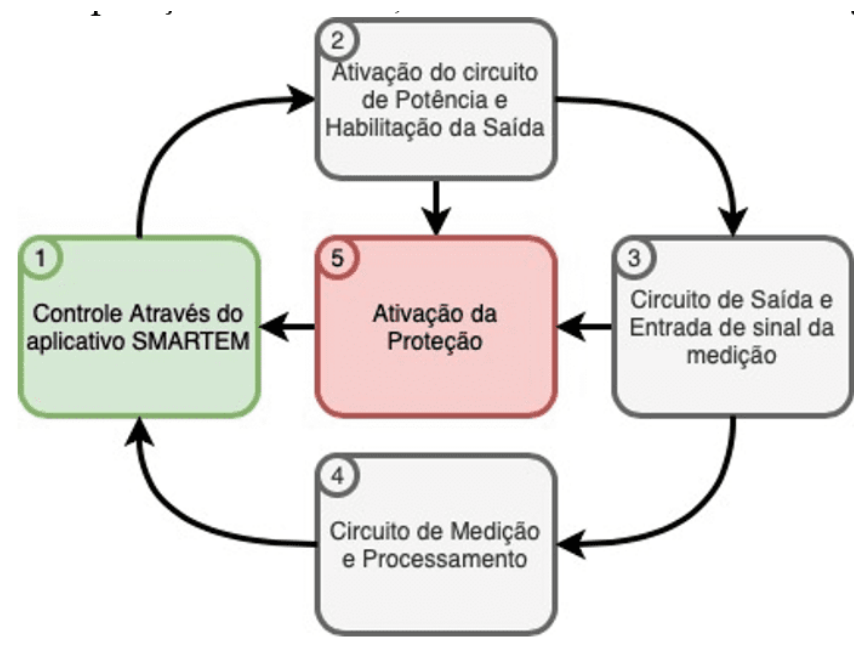


Fonte: Autor.

Cada uma destas operações envolve um ou mais módulos que compõe o hardware e o software do aplicativo que o gerencia conforme pode ser observado na Figura 2, onde cada bloco é enumerado com o mesmo número identificador da respectiva operação em que atua.

Figura 2 - Composição básica de hardware e software (aplicativo) do SMARTEM.

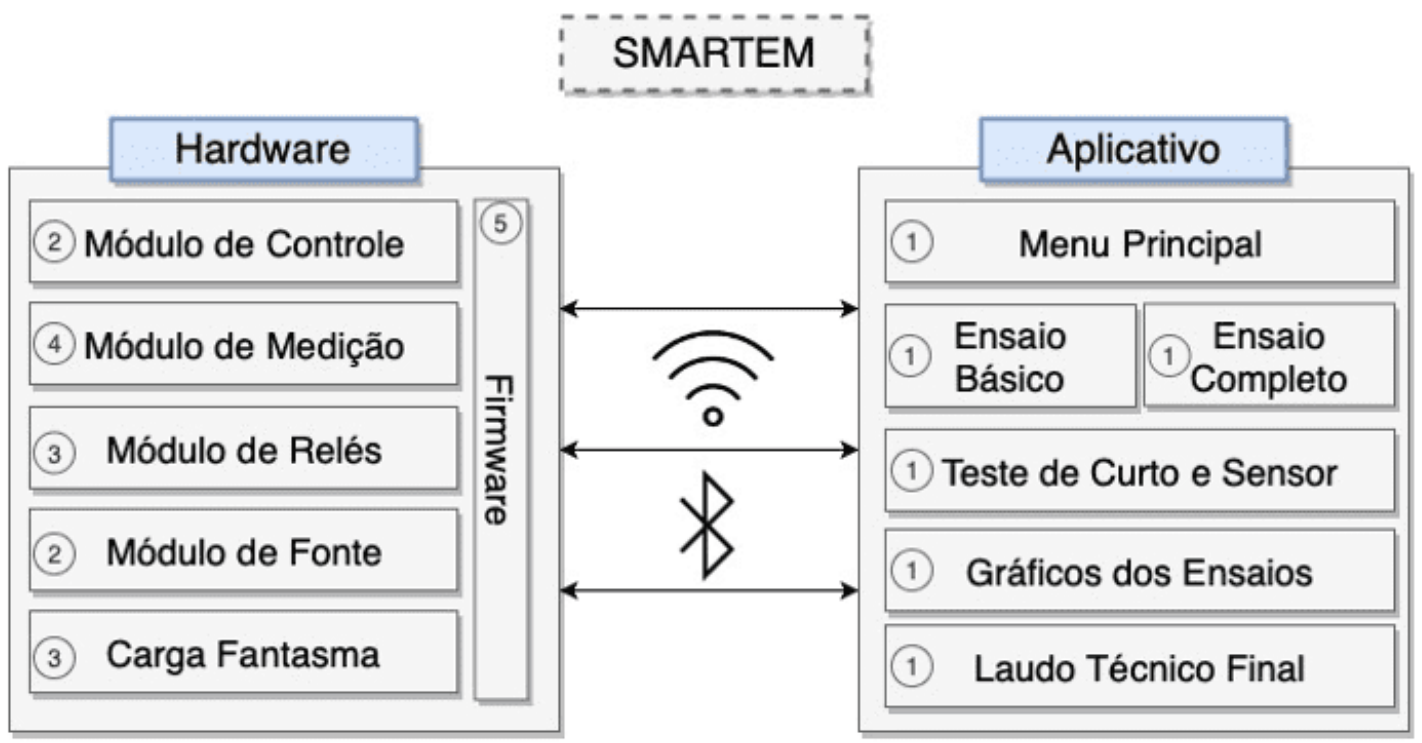

Fonte: Autor.

A seção 3.2 apresenta as principais características elétricas do equipamento que ajudam a compreender melhor os módulos do hardware e do aplicativo descritos nas seções 3.3 e 3.4 , respectivamente.

\subsection{CARACTERÍSTICAS ELÉTRICAS GERAIS}

Para atender aos requisitos de tensão, o SMARTEM utiliza a própria tensão da rede que o alimenta, não sendo necessário, portanto, o uso de uma fonte de tensão controlável. Esta prática é prevista e permitida por [1] e [2]. Dessa forma, a cada ensaio, o equipamento aplica no medidor sob aferição, através do acionamento de relés dedicados a este fim, a tensão da rede que, antes do procedimento, alimentava 
o próprio medidor. Para isso, faz-se uso de um autotransformador toroidal, cujo enrolamento primário é totalmente dedicado ao fornecimento de tensão. Para o caso de aplicação de tensão em campo, a relação de transformação será de 1:1. Mas para o caso de testes em laboratório, utiliza-se diferentes TAPs deste mesmo transformador já que, como mencionado anteriormente, é necessário que a tensão aplicada exceda em 10\%, para medidores eletromecânicos, ou 15\%, para medidores eletrônicos, o valor da tensão nominal.

A medição de tensão é feita através de um divisor resistivo simples de forma que o sinal de tensão fique no range adequado para ser interpretado pelo circuito micro processado. Seu range de leitura de tensão é de 0 a $665 \mathrm{~V}$.

Para atender os requisitos de corrente, o SMARTEM faz uso de uma carga fantasma ou carga virtual. Essa carga não se trata de uma fonte de corrente como em [12]. Ela consiste em um enrolamento secundário no autotransformador com diferentes TAPs para diferentes valores de corrente. Dessa forma, ao se iniciar um ensaio, o secundário deste transformador é curto-circuitado utilizando-se um dos TAPs disponível, gerando a corrente necessária para o respectivo ensaio. A relação de transformação deste transformador é definida de forma a atender os requisitos de corrente especificados para cada ensaio. A Figura 3 contribui para uma melhor compreensão do funcionamento deste arranjo, sendo $n_{4}>n_{3}>n_{2}>n_{2}>>>N_{3}>N_{2}>$ $\mathrm{N}_{1}$.

Figura 3 - Representação do autotransformador utilizado pelo SMARTEM

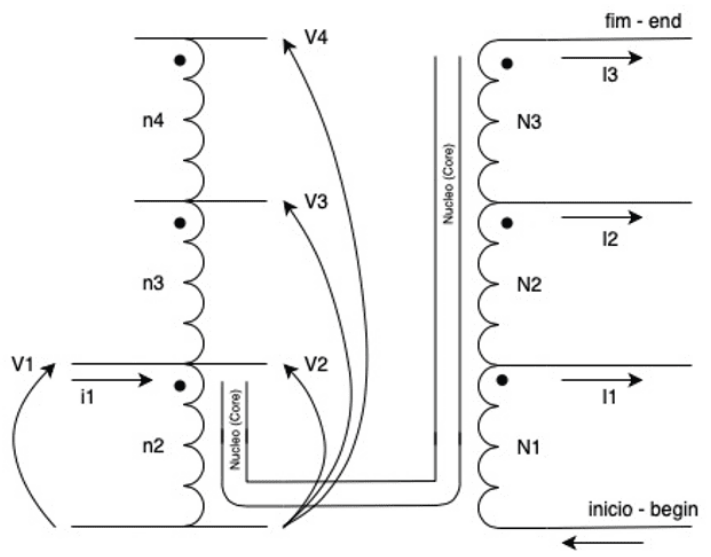




$$
\begin{array}{lllll}
\frac{V_{2}}{V_{1}}=\frac{n_{2}}{n_{2}} & (2) & \frac{V_{3}}{V_{1}}=\frac{n_{2}+n_{3}}{n_{2}} & \text { (3) } & \frac{V_{4}}{V_{1}}=\frac{n_{2}+n_{3}+n_{4}}{n_{2}} \\
\frac{I_{1}}{i_{1}}=\frac{n_{2}}{N_{1}} & \text { (5) } & \frac{I_{2}}{i_{1}}=\frac{n_{2}}{N_{1}+N_{2}} & \text { (6) } & \frac{I_{3}}{i_{1}}=\frac{n_{2}}{N_{1}+N_{2}+N_{3}}
\end{array}
$$

A medição da corrente é feita através de um transformador de corrente (TC) sem gap instalado dentro do equipamento, conectado em paralelo com um resistor shunt para permitir a leitura, pelo sistema micro processado, do sinal gerado pelo TC.

Como pode ser observado na Figura 3, as relações de transformação das tensões para atender os requisitos dos ensaios de tensão da rede, $110 \%$ da tensão e $115 \%$ da tensão, são as relações de um autotransformador comum, que podem ser vistas nas equações (2), (3) e (4). Já para a corrente, as relações, que podem ser vistas nas equações (5), (6) e (7), são estabelecidas para garantir valores de corrente para o ensaio de exatidão, que no caso do SMARTEM são aproximadamente $2.5 \mathrm{~A}, 18 \mathrm{~A}$ e $45 \mathrm{~A} \pm 10 \%$.

O SMARTEM possui também um padrão interno de medição. Este padrão consiste em uma placa micro processada exclusiva para cálculo da energia que passa pelo medidor no momento dos ensaios, permitindo, assim, que o equipamento seja capaz de calcular o erro entre seu padrão interno e o medidor aferido. Com uma resolução de 12 bits e um erro absoluto de $\pm 0.1 \mathrm{Wh}$, o padrão atende os Regulamentos Técnico Metrológicos [1] e [2] que exigem pelo menos $\pm 0.3 \%$. Para o calculo do erro no ensaio de exatidão, a equação (8) é utilizada:

$$
\operatorname{Erro}(\%)=\frac{E_{\text {medidor }}-E_{\text {smartem }}}{E_{\text {smartem }}}
$$

Sendo que um resultado com erro negativo significa que o medidor está lendo uma energia menor do que a que realmente está passando por ele e, neste caso, a concessionária está em prejuízo. Já um resultado com erro positivo indica que o medidor está medindo a mais do que realmente está sendo utilizado e, portanto, o 
cliente está sendo prejudicado. Para ambos os casos, os limites aceitáveis de erros para mais e para menos apresentados nas tabelas 1 e 2 indicam a necessidade ou não da troca daquele medidor.

O padrão interno do SMARTEM também é passível de calibração com ajustes e sem ajustes. Para a calibração sem ajustes, da mesma forma que os medidores de energia comuns, ele emite pulsos que ficam disponíveis para acesso, tornando possível emitir um certificado de calibração do próprio calibrador. Já a calibração com ajustes é feita de fábrica, onde são obtidos e informados ao instrumento os ajustes devidos de ganho e de offset. Estes ajustes são registrados na memória EEPROM do medidor, permitindo que ele faça um auto ajuste, ou auto calibração, com os parâmetros de calibração obtidos de fábrica, toda vez que é ligado.

Como o erro do padrão é absoluto e em Wh, para ensaios com baixa quantidade de pulsos ou revoluções, ou seja, ensaios cuja energia aplicada sobre o medidor para aferição do seu erro é pouca, a imprecisão do equipamento naturalmente será mais significativa. No gráfico da Figura 4 são mostrados ensaios de exatidão, para diferentes quantidades de pulsos, realizados pelo SMARTEM, em um medidor eletrônico com constante Ke igual a 0,625 Wh/pulso e erro conhecido de $-0,08 \%$. Neste caso, o aplicativo sugeriu uma quantidade de 23 pulsos para garantir o erro de $\pm 0,3 \%$ no processo de calibração. Pode ser observado que para uma quantidade de pulsos menor que este valor, a imprecisão fica alta, resultando em uma indicação de um erro de $-0,9 \%$ no caso de apenas 6 pulsos. Já para quantidades iguais ou acima do número de pulsos sugeridos, observa-se que a variação do erro apresentado é de aproximadamente $0,3 \%$, garantindo a manutenção da leitura na faixa $0,3 \%$ exigida por norma. 
Figura 4 - Gráfico representativo da variação do erro para diferentes quantidades de pulsos.

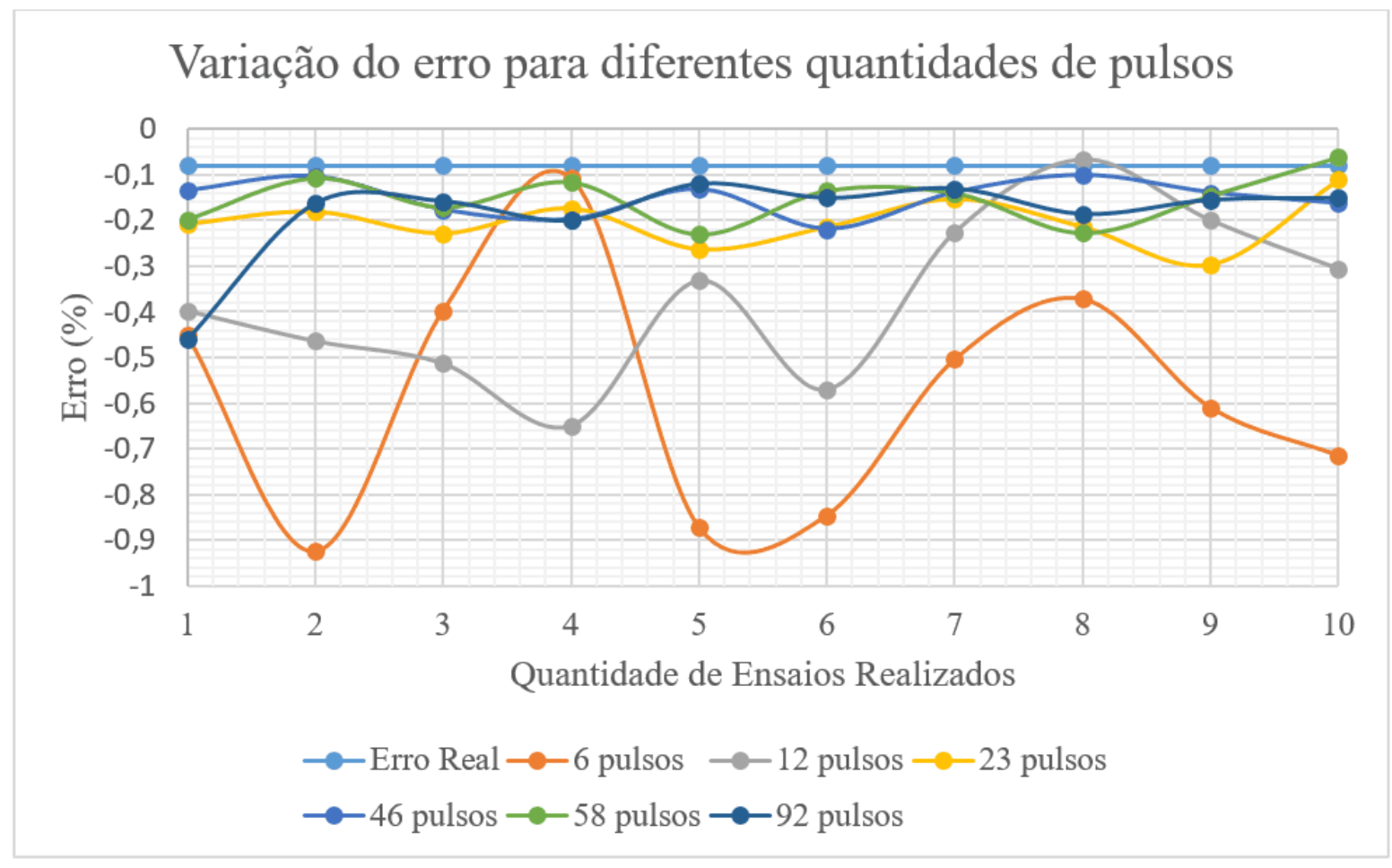

Fonte: Autor.

\subsection{CARACTERÍSTICAS DE HARDWARE}

O diagrama de blocos abaixo procura retratar de forma fiel as composições do hardware do equipamento. Uma fonte de tensão DC alimenta o processador, seus periféricos e, de forma isolada, os relés, para evitar interferência de ruídos devido ao acionamento e desligamento dos mesmos. O módulo de comunicação Bluetooth serve para estabelecer a conectividade entre o aplicativo SMARTEM e o aparelho físico. Já o módulo de comunicação Wi-Fi é utilizado para atualização do firmware do processador sem a necessidade de acessar diretamente o mesmo, uma vez que ela é toda feita via OTA, ou atualização Over The Air.

Durante um ensaio, o processador aciona um grupo de relés que atuam no transformador de forma a selecionar os TAPs adequados para este determinado ensaio. A tensão e corrente fornecidos por esse trafo compõe a saída do equipamento. 
Com isso, o processador recebe as informações de medição obtidas durante o ensaio pelo padrão interno através da comunicação SPI estabelecida entre eles. Esse padrão possui um grupo de ADCs de 12bits, responsáveis pelas leituras da tensão e da corrente que passam no medidor de energia que está sendo aferido. Dessa forma, a função do padrão é medir a energia fornecida pelo próprio dispositivo para o medidor sob teste e informar ao processador. Este, por sua vez, compara, usando a equação (8), o valor da energia fornecida pelo padrão com a energia do medidor, obtida através das revoluções ou pulsos captados pelo sensor fotossensível.

Dentro do equipamento existem três $\mathrm{PCls}$. A PCl de Controle, contém as unidades de processamento e comunicação. Nela são feitas as análises dos dados obtidos dos ensaios bem como os comandos para se iniciar estes ensaios. Assim, os blocos do Processador, do Padrão, da Comunicação Bluetooth, da Comunicação Wi-Fi e de Interpretação dos sinais do sensor fotossensível fazem parte desta placa. Já a PCI de Relés, contém todo o circuito de acionamento eletrônico dos relés, bem como a interconexão com o bloco transformador. Por fim, a placa de alimentação é mais simples e contém a fonte de tensão DC que alimenta, de forma isolada a PCI de Controle e a PCl de Relés.

Figura 5 - Diagrama de blocos representativo do Hardware do equipamento

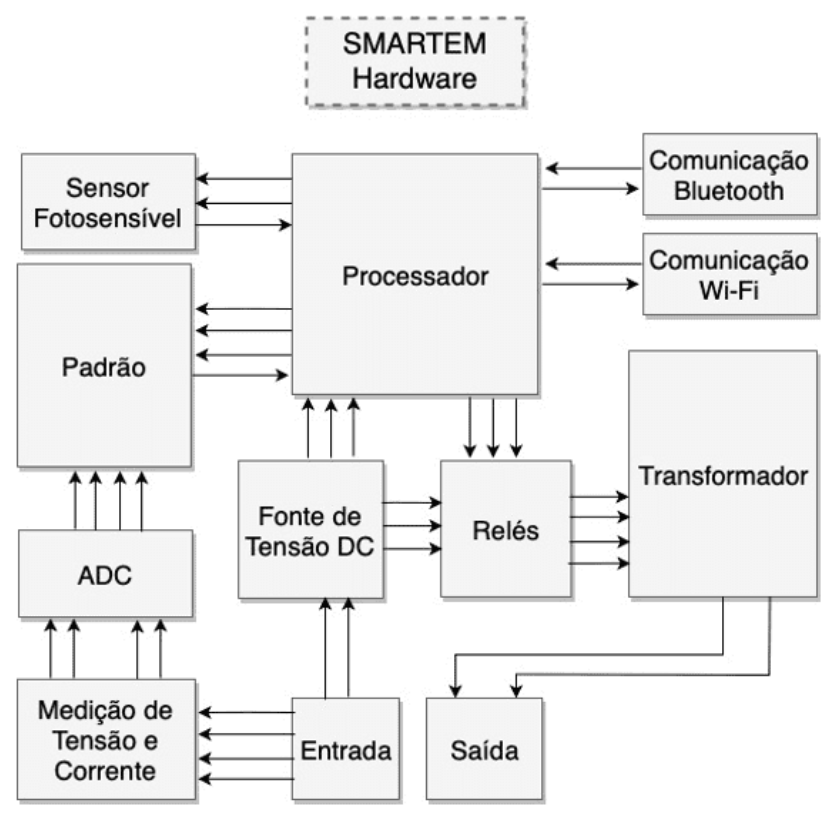


Fonte: Autor.

\subsection{FUNCIONALIDADES DO SOFTWARE - APLICATIVO}

Todas as funcionalidades do calibrador portátil SMARTEM são controladas por meio de um aplicativo, com o mesmo nome do equipamento, disponível para celular ou tablet com o sistema operacional Android®. Ao se iniciar o aplicativo, existem duas opções de funcionalidades: o Ensaio Completo e o Ensaio Básico, conforme mostra a Figura 6.

No primeiro, são exigidos, do operador, um detalhamento mais completo de todo procedimento realizado de forma a contemplar todas as exigências previstas em [1] e [2] para uma aferição por solicitação do usuário/proprietário. Cada informação solicitada pelo aplicativo durante uma visita é relevante para o preenchimento do laudo técnico que será impresso, via comunicação Bluetooth, com a impressora térmica portátil que acompanha o equipamento, logo após finalizada a aferição. Este relatório final foi desenvolvido com base no TOI - Termo de Ocorrência de Irregularidade, previsto no artigo 129, inciso I, da Resolução no 414/2010 da ANEEL [4], que tem por finalidade formalizar a constatação de qualquer irregularidade encontrada nas unidades de consumo dos usuários de energia elétrica, que proporcione faturamento inferior ao real. 
Figura 6 - Tela de definição de ensaios do aplicativo.

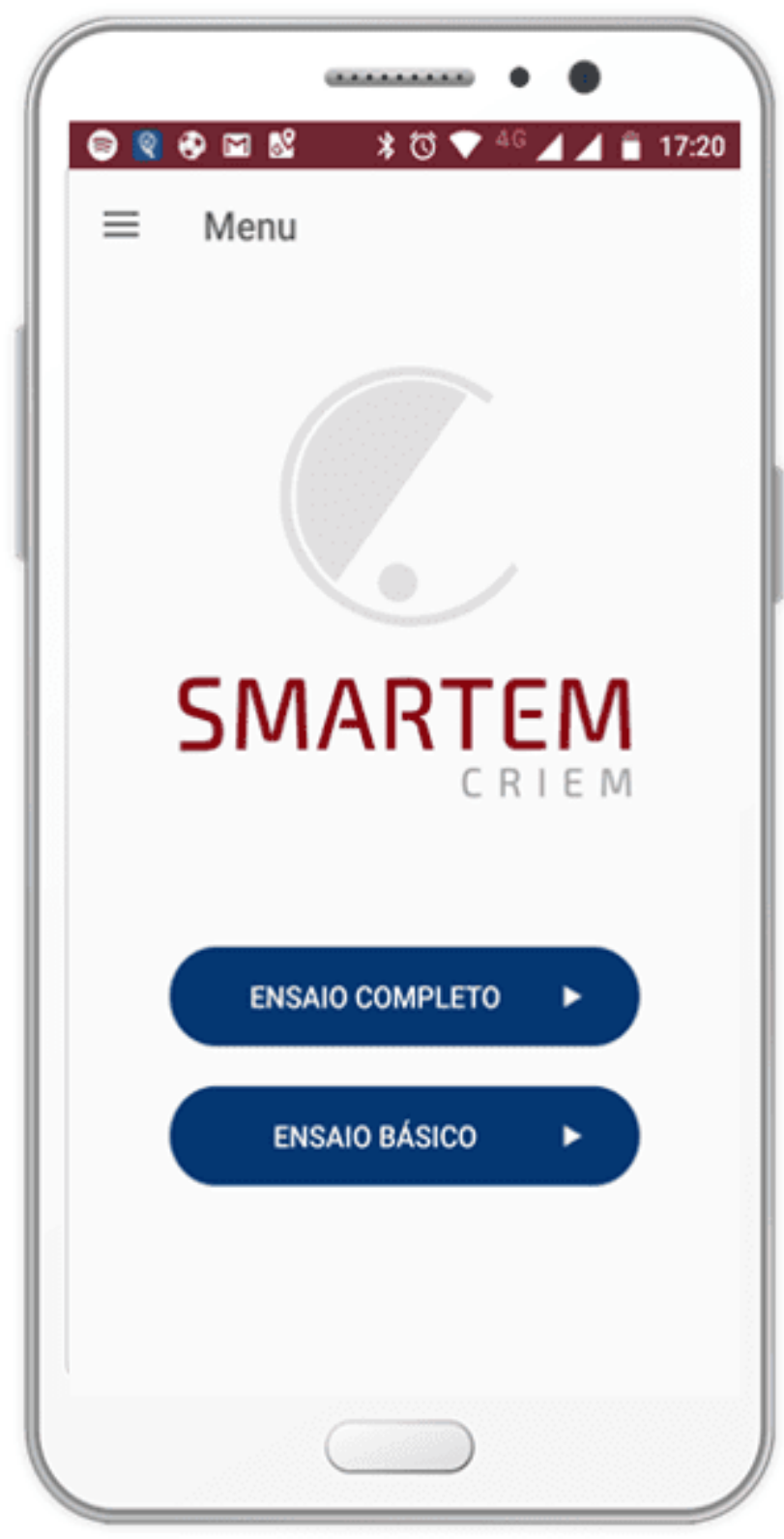

Fonte: Autor. 
Figura 7 - Tela de Ensaios do aplicativo.

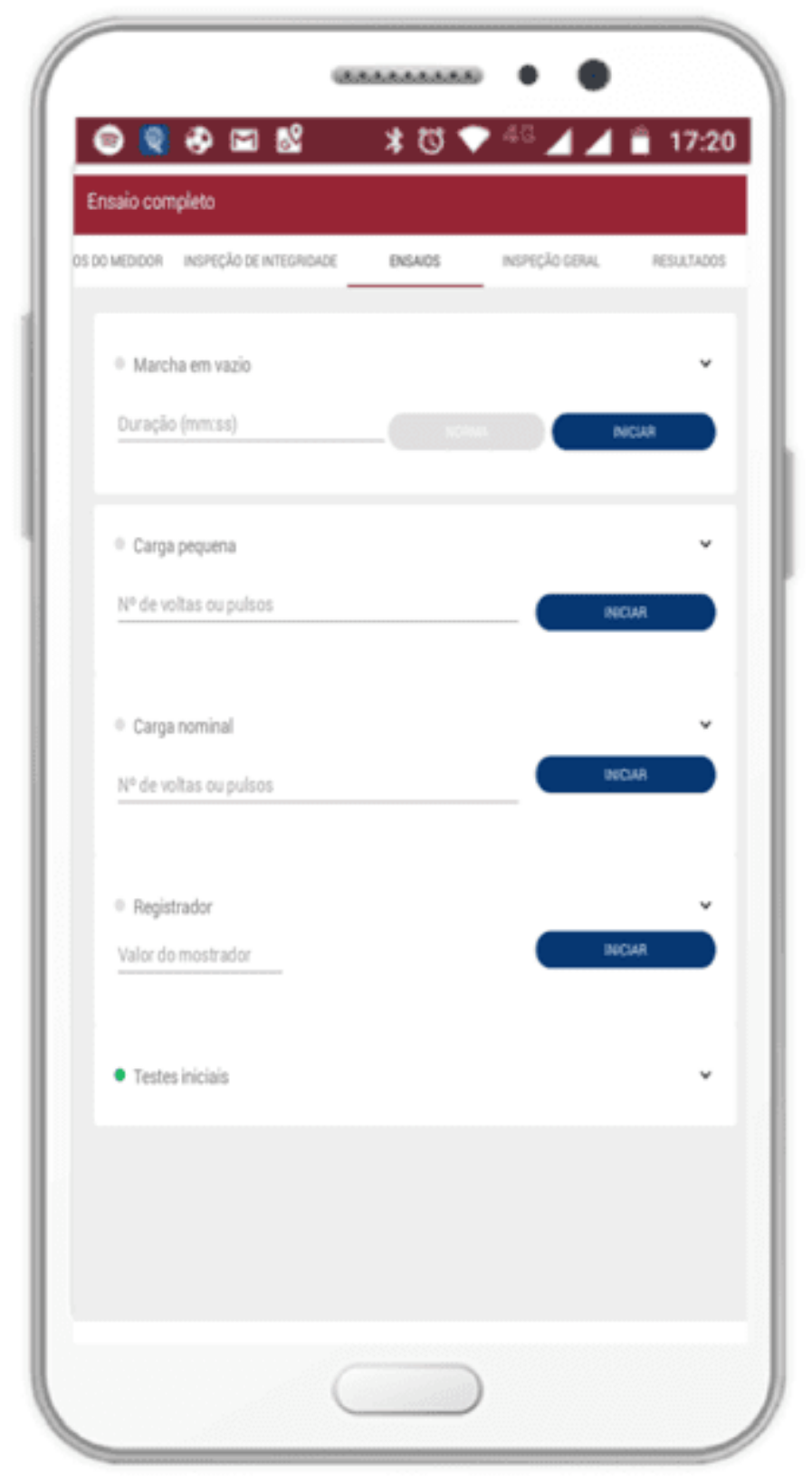

Fonte: Autor. 
Figura 8 - Aplicativo mostra um gráfico de tensão, corrente e andamento do ensaio em tempo real.

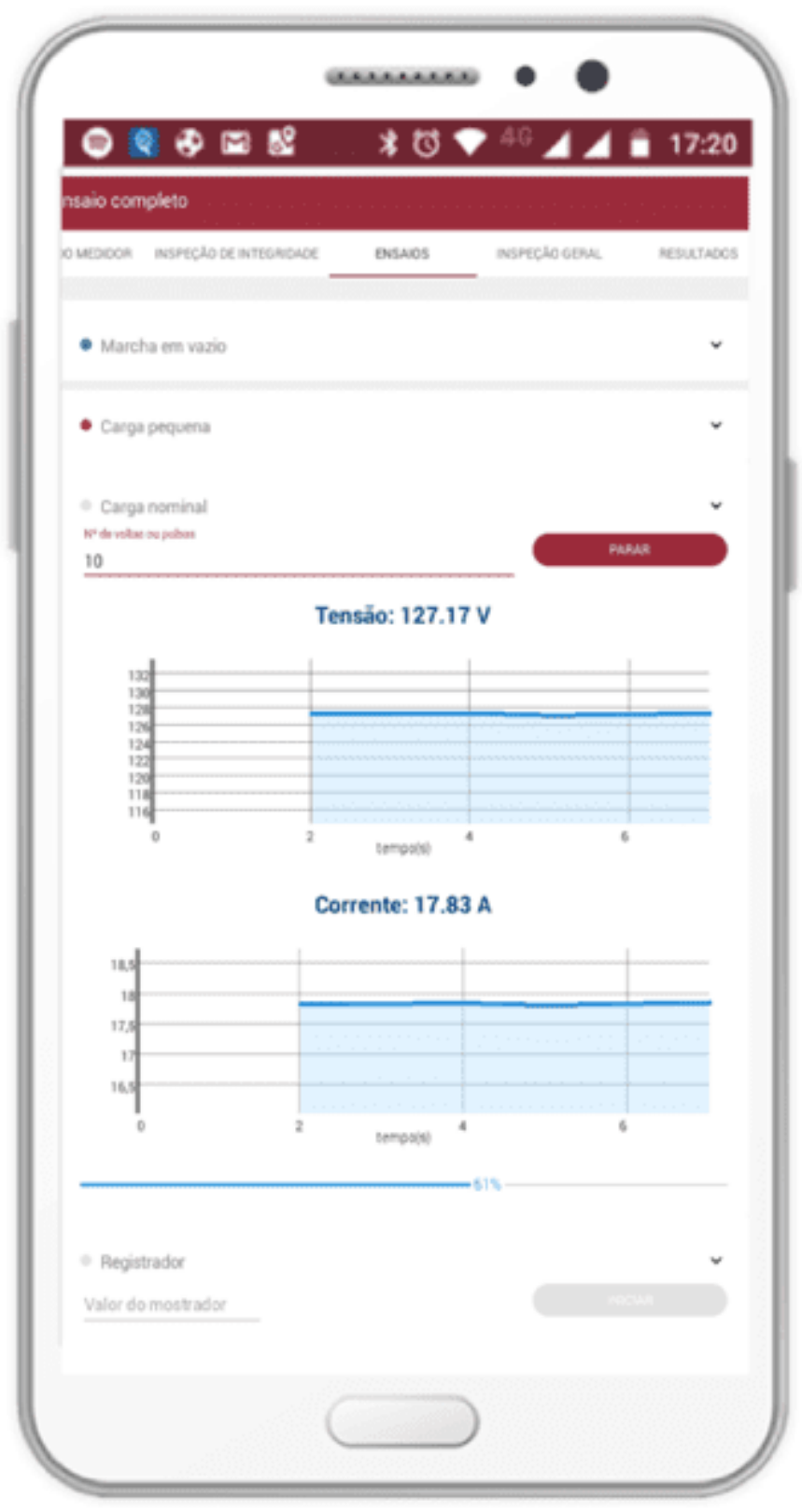

Fonte: Autor.

Já o ensaio Básico, a fim de tornar o processo mais rápido e dinâmico, são disponibilizados para o operador os 4 ensaios exigidos pela norma apenas para averiguação da situação do medidor. Um laudo apenas informativo, ou seja, sem os dados de procedimentos necessários no TOI, contendo apenas o veredito final de 
cada ensaio é emitido e pode também ser impresso de forma similar ao anterior. A definição de duas formas de operação distintas se deu para que a concessionária ou empresa responsável pudesse optar pela aferição mais curta e rápida, com cerca de 25 min, mas sem todo o detalhamento do processo, ensaio básico, ou escolher o ensaio completo, com um tempo um pouco maior, de aproximadamente 35 a $40 \mathrm{~min}$ de aferição, mas com a possibilidade de se emitir e imprimir um laudo técnico contemplando todas as informações necessárias do TOI.

Antes de se iniciar qualquer ensaio em um medidor de energia, o calibrador SMARTEM solicita ao operador os dados essenciais do medidor de energia a ser aferido e, sem seguida, realiza dois testes iniciais. O primeiro é um teste de curto, feito para assegurar que o operador, ou técnico responsável, não tenha feito uma conexão em curto, o que pode resultar na queima do medidor sob teste. Este teste sendo aprovado, libera um segundo procedimento, para auxilio do posicionamento correto do sensor fotossensível. Neste caso, o equipamento auxilia o operador a posicionar o sensor de forma que os pulsos ou revoluções estejam sendo detectados pelo instrumento para que, dessa forma, não seja necessário que o técnico ajuste o sensor novamente até que a aferição finalize.

Após os testes iniciais, e o preenchimento de alguns dados importantes para o relatório final, no caso do Ensaio Completo, os 4 ensaios são liberados para serem realizados conforme Figura 7. São disponibilizados os ensaios Marcha em Vazio, Carga Maior, Carga Pequena e Registrador, conforme descrito anteriormente. Para cada um desses ensaios, são mostrados, em tempo real, as informações de tensão e corrente medidos e a porcentagem do andamento do ensaio como pode ser visto na Figura 8. Ao final de cada um deles, o aplicativo informa se o medidor foi aprovado, ou não, no ensaio conforme as normas vigentes. As informações de aprovação ou desaprovação constam no laudo técnico final. No caso dos ensaios de exatidão, o erro percentual do medidor sob aferição também é apresentado. Já no caso do ensaio do registrador, ou mostrador, o aplicativo permite que o usuário faça um registro fotográfico, caso o celular ou tablet possua este recurso, do instante anterior e posterior ao ensaio para confirmar ou comprovar que foi aplicado $1.0 \mathrm{kWh}$ de energia 
durante o ensaio. Estas fotos ficam armazenadas em uma pasta, com nome SMARTEM, na memória interna do celular ou tablet.

Por fim, o menu superior da tela inicial do aplicativo apresenta algumas opções interessantes para o usuário. No item Configurações, é possível salvar um arquivo com extensão .xlsx contendo o cadastro do banco de dados de todos os medidores que a concessionaria ou empresa responsável possui de forma a anular a necessidade de se preencher os dados necessários do medidor a ser aferido durante a inspeção, reduzindo ainda mais o tempo de calibração em campo. Além disso, o item Histórico apresenta um histórico de todas as aferições realizadas até então, com suas respectivas fotos, caso houver, e possibilidade de reimpressão do relatório emitido naquela calibração.

\subsection{CERTIFICAÇÕES}

O equipamento foi certificado como CAT IV - 300V, atendendo assim aos padrões de segurança estabelecidos pelo padrão internacional IEC61010-1 [6] e pela norma brasileira NBR5410 [5], anexo E, uma vez que se trata de um instrumento com tensão de operação de até $300 \mathrm{~V}$ que opera com medidores de energia na entrada de instalações elétricas.

Além disso, no Brasil, qualquer equipamento com capacidade de se comunicar utilizando tecnologia Bluetooth ou Wi-Fi deve ser testado e aprovado pela Agência Nacional de Telecomunicações - Anatel. Com isso, fez-se necessário obter-se a homologação deste produto tanto para a comunicação Wi-Fi quanto para a comunicação Bluetooth garantindo que as frequências utilizadas estão dentro das permitidas pela Anatel.

E finalmente, com a intenção de atestar a performance do produto para sua principal proposta de operação, o SMARTEM foi calibrado e aprovado no Laboratório Eletrônico de Medição - LEM da CEMIG pelos Padrões de Referência Monofásicos marca Radian, modelo RM-11. O LEM é um laboratório acreditado pelo INMETRO - Instituto Nacional de Metrologia, com Normalização e Qualidade Industrial e certificado pelo 
Bureau Veritas Quality International - BVQI no Sistema de Gestão da Qualidade - ISO 9002, o que garante ao equipamento a confiabilidade e a credibilidade necessária para operar no mercado.

\section{SOBRE O INSTRUMENTO E SEUS ACESSÓRIOS}

\subsection{USO EM CAMPO}

$\mathrm{Na}$ Figura 9 pode-se observar a unidade do instrumento de calibração portátil SMARTEM juntamente com a indicação da função de cada um dos seus componentes externos apresentados na tabela 3.

Para a realização de uma aferição faz-se necessária a desconexão da rede elétrica e da carga ou cliente como mencionado anteriormente. Os cabos da própria rede elétrica são usados para energizar o SMARTEM e gerar as grandezas elétricas para a realização dos ensaios. A figura 9 exemplifica como é feita a ligação em medidores monofásicos. No painel frontal do equipamento, um diagrama foi inserido para auxiliar neste processo de instalação do equipamento no medidor.

Figura 9 - Equipamento SMARTEM.

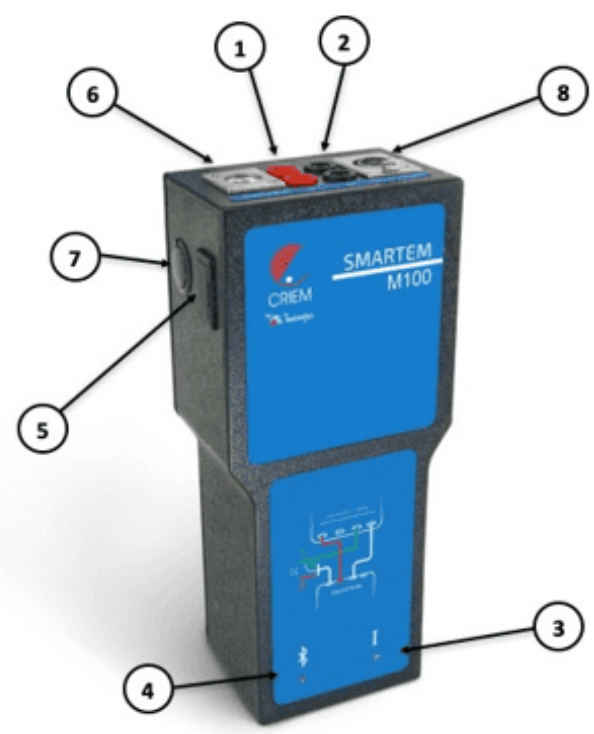

Fonte: Autor. 
O kit completo do calibrador contém seu manual de operação, um cabo de alimentação, com possibilidade de conexão para fase, neutro e terra. Além disso, possui dois cabos de corrente de $6 \mathrm{~mm}^{2}$, que conectam, em série, a saída e o retorno do equipamento, conforme figura 8 e tabela 3 , com o circuito de corrente do medidor e dois jumpers para conectar, em série, em medidores polifásicos, o circuito de corrente das diferentes fases.

Tabela 3 - Funções dos componentes externos do SMARTEM. Fonte: João Vítor Marques Antunes

\begin{tabular}{|c|c|c|c|c|c|}
\hline № & NOME & FUNÇÃO & № & NOME & FUNÇÃO \\
\hline 1 & Saída & Saída de Corrente & 5 & Proteção & $\begin{array}{l}\text { Fusível de ação } \\
\text { rápida }\end{array}$ \\
\hline 2 & Retorno & $\begin{array}{l}\text { Conector de } \\
\text { Retorno do Circuito }\end{array}$ & 6 & Alimentação & $\begin{array}{ll}\text { Conector } & \text { para } \\
\text { alimentação } & \text { VAC } \\
(60 \mathrm{~Hz}) \mathrm{F} / \mathrm{N} & \end{array}$ \\
\hline 3 & $\begin{array}{l}\text { LED de } \\
\text { Corrente }\end{array}$ & $\begin{array}{ll}\text { LED } & \text { amarelo } \\
\text { habilitado } & \text { quando } \\
\text { OUTPUT } & \text { conduz } \\
\text { corrente } & \end{array}$ & 7 & ON / OFF & $\begin{array}{l}\text { Chave liga-desliga } \\
\text { do equipamento }\end{array}$ \\
\hline 4 & $\begin{array}{l}\text { LED do } \\
\text { Bluetooth }\end{array}$ & $\begin{array}{l}\text { LED vermelho } \\
\text { indicador de } \\
\text { conexão Bluetooth }\end{array}$ & 8 & $\begin{array}{l}\text { Unidade } \\
\text { Ótica }\end{array}$ & $\begin{array}{l}\text { Unidade Ótica de } \\
\text { detecção de pulsos } \\
\text { de medidores }\end{array}$ \\
\hline
\end{tabular}

Ao ser executado o teste a vazio ou o teste de exatidão, no qual se faz uma comparação da medição feita pelo medidor sob análise com a medição do padrão interno do calibrador, é necessário que seja feita a leitura dos pulsos emitidos pelo medidor, no caso de um medidor eletrônico, ou as revoluções do disco, no caso de um medidor eletromecânico. Para isso, o calibrador conta com dois adereços. O primeiro, e mais preciso, é um sensor fotossensível capaz de detectar pulsos de LED e também a marca preta do disco. Este sensor é fixado através de uma haste encaixada no pino de neutro do medidor, o que garante o aterramento do mesmo e 
maior estabilidade. Todos estes itens são acomodados em uma maleta rígida e própria para transporte.

Para que o equipamento seja autônomo na execução de suas funcionalidades, alguns itens opcionais podem ser incluídos. Estes itens consistem um tablet, com sistema operacional Android®, mostrado na Figura 10 e o aplicativo SMARTEM, previamente instalado, e uma impressora térmica Bluetooth portátil para impressão do laudo técnico ao fim do processo de aferição.

Figura 10 - Tablet é um item opcional do equipamento.

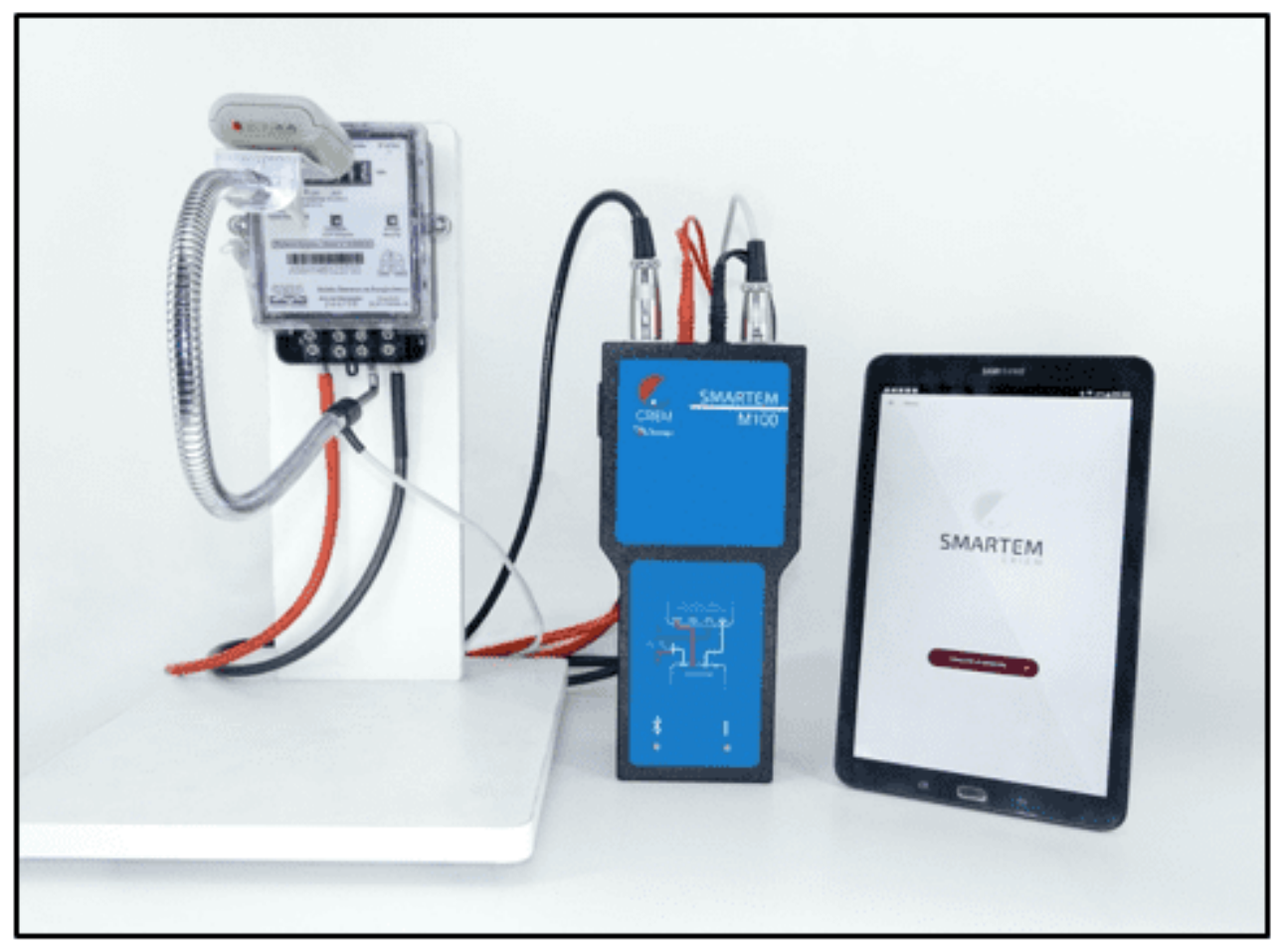

Fonte: Autor.

Relacionam-se, a seguir, as características de especificação técnica do calibrador portátil SMARTEM:

- Constante de Pulsos do Padrão: $0.01 \mathrm{Wh} /$ pulso

- Exatidão do padrão + incerteza: $\pm 0.3 \%$

- Medição de Tensão: 0 a 665V 
- Medição de Corrente: 0 a 65A

- Corrente máxima de fornecimento: $45 \mathrm{~A} \pm 10 \%$

- Frequência: $45 \mathrm{a} 65 \mathrm{~Hz}$

- Consumo: 80 VA

- Temperatura de operação: 0 a $60^{\circ} \mathrm{C}$

- Categoria de Sobretenção: CAT IV - 300V

- Dimensões: $7.0 \times 11.0 \times 24.0 \mathrm{~cm}$

- Peso: $1.5 \mathrm{~kg}$

O calibrador portátil SMARTEM se encontra comercialmente disponível, em fase de vendas e, apesar de recente, já está sendo utilizado para aferição de medidores em algumas concessionárias de energia e empresas prestadoras de serviços na área, que atuam no Brasil, como CEMIG e ENEL.

É interessante mencionar que, além de ser utilizado para calibração de medidores em campo, via solicitação do cliente, função para a qual foi desenvolvido, o SMARTEM está atuando como uma importante ferramenta no combate a irregularidades e fraudes, segundo as empresas que adquiriram o equipamento. Isto se dá uma vez que o mesmo identifica, no local, erros consideráveis devido a adulterações ilegais nos medidores de energia ou, em caso de constatada uma irregularidade no local e atestado o funcionamento adequado do medidor pelo equipamento, acusa probabilidade de "gato na rede", facilitando o trabalho de inspeção de irregularidades, trazendo economia para essas empresas.

\subsection{USO EM LABORATÓRIO}

Como mencionado anteriormente, o SMARTEM também foi desenvolvido com funcionalidades para uso em laboratório, já que aplica níveis de tensão diferentes para medidores eletrônicos ou eletromecânicos como especificado em [1] e [2]. 
Figura 11 - Mesa de calibração monofásica SMARTEM.

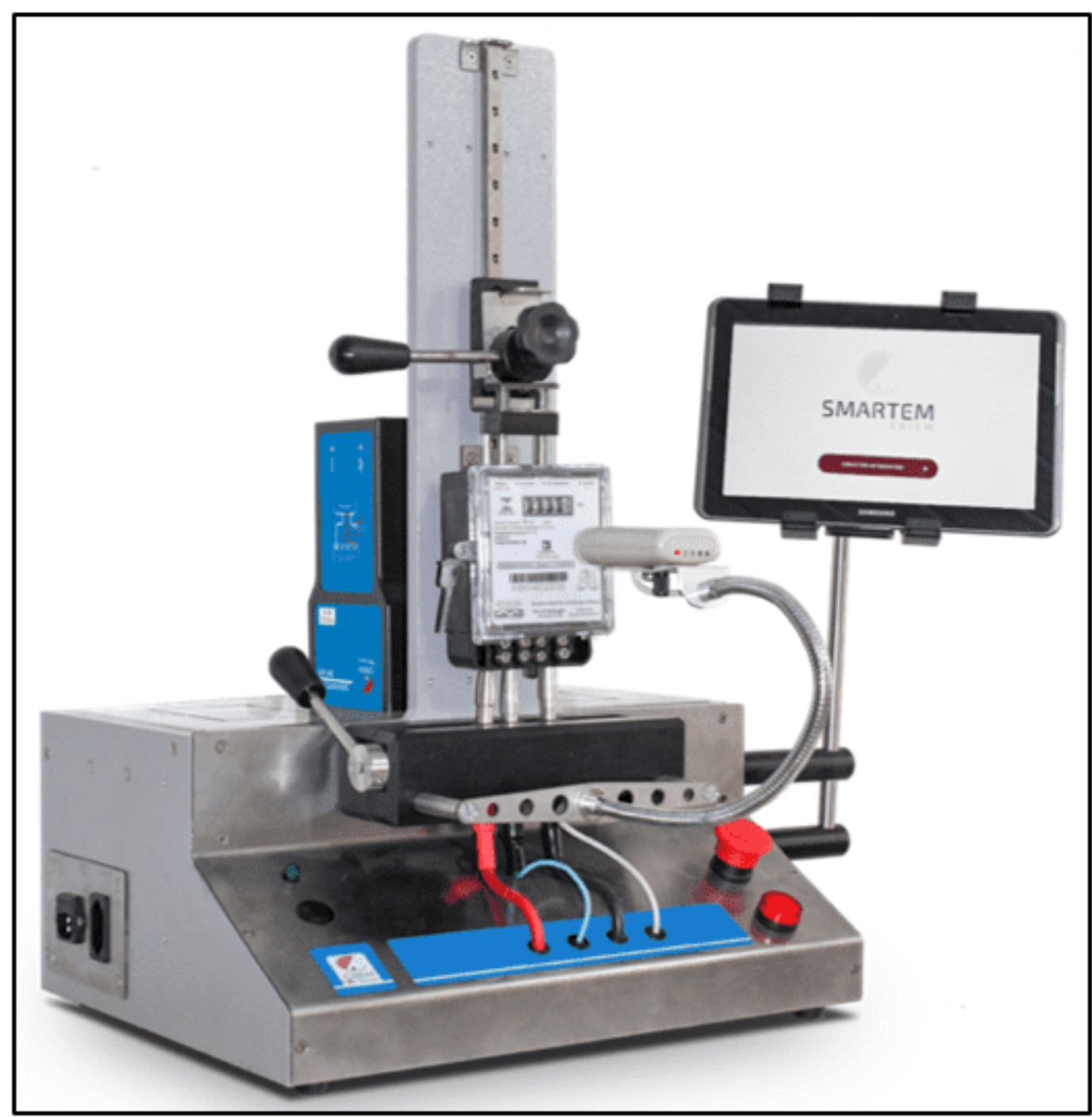

Fonte: Autor.

Para isso, existe a Mesa Monofásica de Calibração SMARTEM para laboratório. É uma versão simplificada e monofásica das atuais mesas de calibração descritas na introdução deste artigo. Ela conta com um encaixe na sua superfície superior para um equipamento portátil SMARTEM tornando possível o mesmo instrumento ser utilizado tanto em campo, quanto em laboratório, ao ser encaixado na parte traseira do Módulo. A vantagem de se usar o Módulo em laboratório é o seu sistema de encaixe rápido 
que permite troca de medidores aferidos de forma mais dinâmica tornando mais rápido o processo de calibração sem ajustes no laboratório.

\section{CONCLUSÕES}

O calibrador portátil de medidores de energia desenvolvido e apresentado neste artigo se propõe a aferir, ou calibrar sem ajustes, medidores de energia monofásicos e polifásicos emitindo e imprimindo um laudo técnico final, de forma a atender [1] e [2] para verificação por solicitação do usuário. Com ele é possível realizar os 4 ensaios exigidos por norma, sendo eles o teste a vazio, o ensaio de exatidão, realizado com dois valores de corrente distintos, e o ensaio do mostrador, no qual se aplica $1 \mathrm{kWh}$ no medidor sob análise. Equipamentos com propostas similares possuem padrões para calibrar os medidores, mas não possuem carga, como em [7] e [9], necessitando de um equipamento auxiliar para este quesito, normalmente uma carga fantasma ou fontes de tensão e corrente, como em [11] e [12], o que aumenta seu tamanho e custo, dificultando seu uso em campo.

O SMARTEM faz uso de um microprocessador para integrar um padrão de energia a uma carga fantasma de até $50 \mathrm{~A}$ em um equipamento de baixo peso, volume e custo, atendendo sua proposta de ser um instrumento portátil. Este equipamento pode, também, auxiliar as concessionárias de energia no processo de inspeção de irregularidades ao aferir o medidor e constatar erros inconsistentes, causados por adulterações ilegais neste medidor.

Seu uso impacta no processo atual de verificação por solicitação de usuário uma vez que reduz os custos operacionais envolvidos, como transporte, troca, aferição laboratorial e armazenamento em mais de $90 \%$ dos casos, em geral, por se tratarem de medidores em bom estado de funcionamento, trazendo uma economia de quase 1,2 milhão em 3 anos segundo [9]. Somado a isso, o equipamento também reduz o tempo de aferição, que poderia levar até 30 dias, para aproximadamente $40 \mathrm{~min}$, gerando e imprimindo um laudo técnico ao fim da calibração, na presença do cliente, trazendo maior transparência e confiabilidade para o processo. Além disso, a possibilidade de utilização deste equipamento em laboratório, por meio das mesas de 
calibração monofásica e, mais adiante, a trifásica, com a praticidade do encaixe de ate 3 calibradores SMARTENs, faz do instrumento uma opção de mercado viável econômica e tecnicamente.

Portanto, o calibrador portátil SMARTEM, além de atender adequadamente as normas técnicas vigentes, possui carga própria e pode ser controlado por um aplicativo, para celular ou tablet com Android $\AA$, simples e intuitivo capaz de emitir e imprimir um relatório com detalhamento de todo o ensaio ao final do processo de calibração. Tratase de um instrumento de fabricação nacional, garantindo custos e prazos de manutenção e assistência técnica mais curtos, comparados a equipamentos importados, e, por fim, traz maior eficiência e agilidade para o processo de calibração por solicitação do usuário, reduzindo significativamente prazos e custos de operação. Considera-se, assim, que o propósito de desenvolvimento dessa solução de Engenharia foi alcançado, inovando em características importantes e desejáveis, como a carga própria, e na solução autônoma, envolvendo hardware e software, que permite a operação ser conclusiva, além de oferecer informações acionáveis aos gestores, quando irregularidades são detectadas.

\section{REFERÊNCIAS}

[1] INMETRO. Portaria Inmetro № 587, de 05 de novembro de 2012, Regulamento Técnico Metrológico de Medidores de Energia Eletrônicos, 2012b.

[2] INMETRO. Portaria Inmetro № 285, de 11 de agosto de 2008, Regulamento Técnico Metrológico de Medidores de Energia Eletromecânicos, 2008.

[3] INMETRO. Portaria Inmetro o 232, de 08 de maior de 2012. Vocabulário Internacional de Metrologia VIM, 2012a.

[4] ANEEL Agencia Nacional de Energia Elétrica. Resolução normativa n414/2010.

[5] ABNT NBR 5410:2004, Instalações Elétricas de Baixa Tensão, 2008. 
[6] IEC 61010-1: "Safety requirements for electrical equipment for measurement, control, and laboratory use", 2010

[7] A. Delle Femine, D. Gallo, C. Landi, M. Luiso, "Measurement equipment for on-site calibration of energy meters", Proc. IEEE IMTC, pp. 1-6, 2007-May.

[8] A. Delle Femine, D. Gallo, C. Landi, M. Luiso, "Advanced Instrument for Field Calibration of Electrical Energy Meters", IEEE Transactions on Instrumentation and Measurement, Volume 58, Issue 3, March 2009 Page(s):618-625, issn: 00189456

[9] Rios, L. R. F., Batista J.P.A., Ribeiro F. R., Diório, F. A., Mafra Jr., J. J., Ribeiro, C. A. S. Padrão de Energia para Calibração de Medidores em Laboratório ou em Campo, 2010.

[10] COUTO, Bruno de Carvalho do. Comparação interlaboratorial em ensaios de medidores de energia elétrica. 2016. 81f. Trabalho de Conclusão de Curso de Mestrado em Metrologia e Qualidade - Instituto Nacional de Metrologia, Qualidade e Tecnologia, Duque de Caxias, 2016.

[11] G. Aurilio, D. Gallo, C. Landi, M. Luiso, "AC Electronic Load for on-site calibration of Energy Meters", Proceedings of IEEE International Instrumentation and Measurement Technology Conference I2MTC 2013, Minneapolis, MN, USA, 6-9 May 2013

[12] Z. Mitrovic, I. Zupunski, "Stable source of AC voltage and current", IMTC 2004Instrumenttation and Measurement Technology Conference, pp. 18-20, May 2004. 


\section{ANEXO}

IMAGENS E TABELAS VERSÃO EM INGLÊS
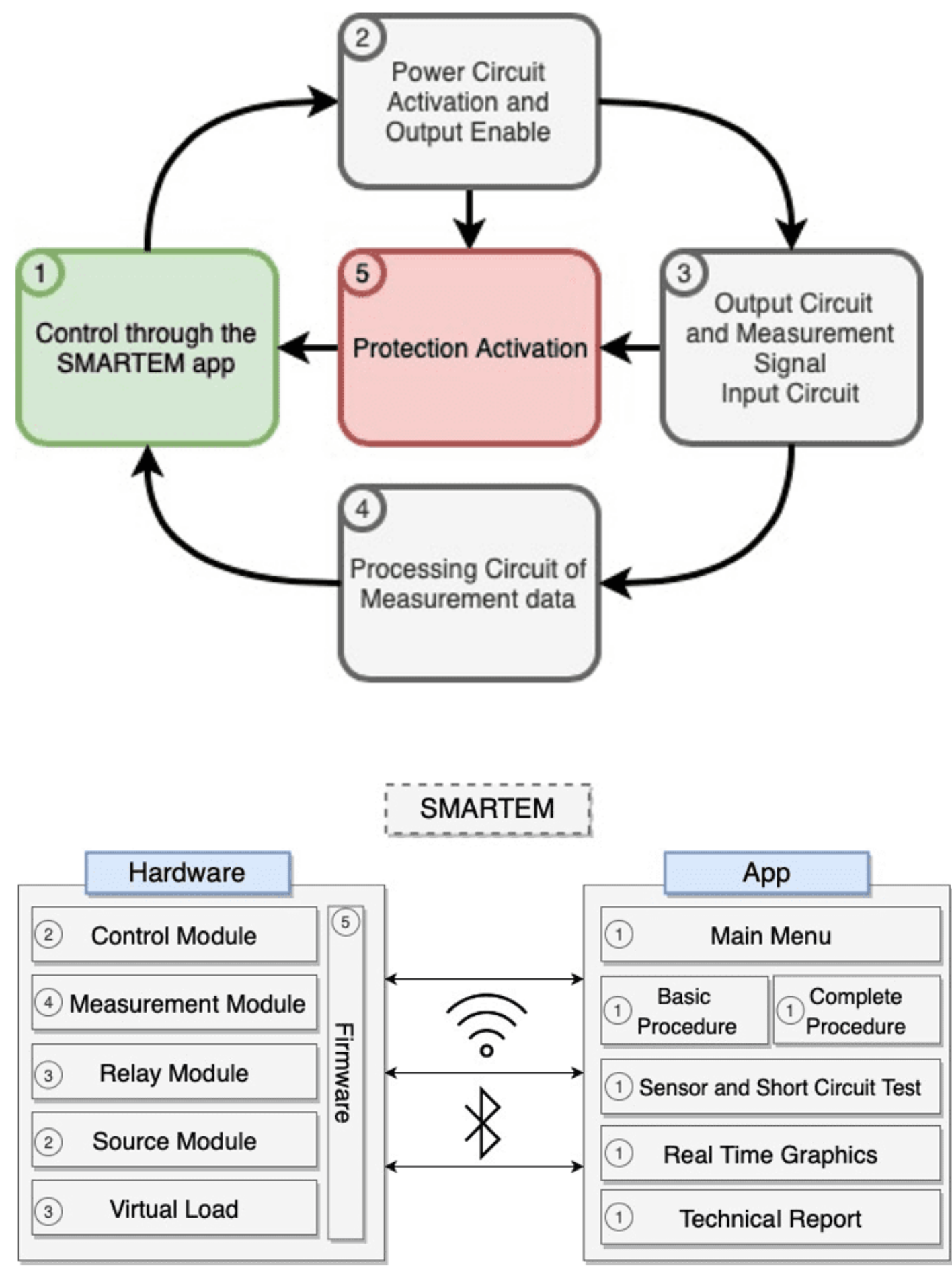


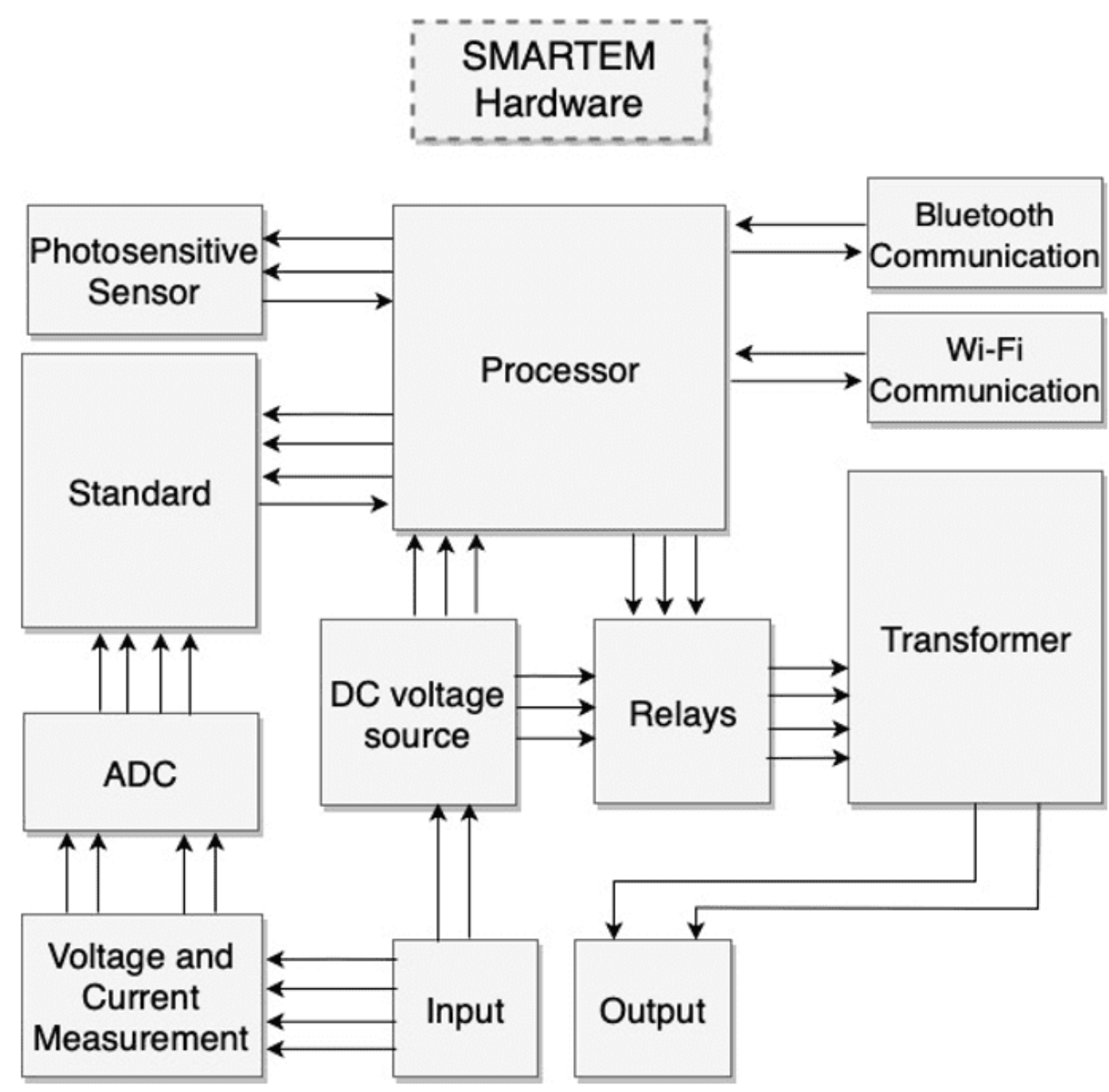

\begin{tabular}{|l|l|l|l|l|l|}
\hline № & NAME & FUNCTION & № & NAME & FUNCTION \\
\hline 1 & Output & Current Output & $\mathbf{5}$ & Protection & Fast acting fuse \\
\hline 2 & Return & $\begin{array}{l}\text { Return Circuit } \\
\text { Connector }\end{array}$ & $\mathbf{6}$ & Source & $\begin{array}{l}\text { Vac power } \\
\text { connector }(60 \mathrm{~Hz}) \\
\text { F / N }\end{array}$ \\
\hline 3 & $\begin{array}{l}\text { Current } \\
\text { LED }\end{array}$ & $\begin{array}{l}\text { Yellow LED } \\
\text { enabled when } \\
\text { OUTPUT } \\
\text { conducts current }\end{array}$ & ON / OFF & $\begin{array}{l}\text { Equipment power } \\
\text { switch }\end{array}$ \\
\hline
\end{tabular}




\begin{tabular}{|c|c|c|c|c|c|}
\hline 4 & $\begin{array}{l}\text { Bluetooth } \\
\text { LED }\end{array}$ & $\begin{array}{l}\text { Red LED } \\
\text { Bluetooth } \\
\text { enabled when } \\
\text { connection is } \\
\text { established }\end{array}$ & 8 & $\begin{array}{l}\text { Photosensitive } \\
\text { unit }\end{array}$ & $\begin{array}{l}\text { Optical pulse } \\
\text { detection unit }\end{array}$ \\
\hline
\end{tabular}

Enviado: Dezembro, 2019.

Aprovado: Janeiro, 2020. 